\title{
Hyperekplexia in neonates
}

\author{
V Praveen, S K Patole, J S Whitehall
}

\begin{abstract}
Hyperekplexia (startle disease) is a rare non-epileptic disorder characterised by an exaggerated persistent startle reaction to unexpected auditory, somatosensory and visual stimuli, generalised muscular rigidity, and nocturnal myoclonus. The genetic basis is a mutation usually of the arginine residue 271 leading to neuronal hyperexcitability by impairing glycinergic inhibition. Hyperekplexia is usually familial, most often autosomal dominant with complete penetrance and variable expression. It can present in fetal life as abnormal intrauterine movements, or later at any time from the neonatal period to adulthood. Early manifestations include abnormal responses to unexpected auditory, visual, and somatosensory stimuli such as sustained tonic spasm, exaggerated startle response, and fetal posture with clenched fists and anxious stare. The tonic spasms may mimic generalised tonic seizures, leading to apnoea and death. Consistent generalised flexor spasm in response to tapping of the nasal bridge (without habituation) is the clinical hallmark of hyperekplexia. Electroencephalography may show fast spikes initially during the tonic spasms, followed by slowing of background activity with eventual flattening corresponding to the phase of apnoea bradycardia and cyanosis. Electromyography shows a characteristic almost permanent muscular activity with periods of electrical quietness. Nerve conduction velocity is normal. No specific computed tomography findings have been reported yet. Clonazepam, a gamma aminobutyric acid (GABA) receptor agonist, is the treatment of choice for hypertonia and apnoeic episodes. It, however, may not influence the degree of stiffness significantly. A simple manoeuvre like forced flexion of the head and legs towards the trunk is known to be life saving when prolonged stiffness impedes respiration. (Postgrad Med f 2001;77:570-572)
\end{abstract}

Keywords: hyperekplexia; neonates; startle

Department of Neonatology, Kirwan Hospital for Women, Townsville, QLD 4817, Australia

V Praveen

S K Patole

J S Whitehall

Correspondence to: Dr Patole

SANJAY_PATOLE@

health.qld̄.gov.au

Submitted 9 January 2001 Accepted 12 April 2001 reported a family of 24 individuals with this disorder which he named hyperexplexia (Kok's disease) after the Greek word for startle. ${ }^{56} \mathrm{~A}$ year later Gastaut and Villeneuve reported 12 patients without a family history of exaggerated startle and corrected the Greek spelling to hyperekplexia which has been adopted since. ${ }^{7}$

\section{Introduction}

Startle reflex, a normal reticular and cortical reflex is elicited to a minor degree in normal newborns and infants. ${ }^{8}$ It is a basic alerting reaction consisting of facial grimacing with blinking, followed by involuntary movements of head flexion, hunching of shoulders, adduction of the arms, and flexion of the trunk and the knees, causing falling without a protective reaction. ${ }^{910}$ It appears in infancy at the same time as the Moro reflex, and becomes more noticeable as the Moro reflex disappears. ${ }^{11}$ When a pathologically exaggerated startle response interferes with normal activities, causing apnoea and frequent falls and injuries, the pathological state is termed as startle disease or hyperekplexia. ${ }^{310}$ Hyperekplexia $^{10}$ may occur in a minor form in which the startle response is exaggerated from normal, or a major form in which patients present with generalised muscular rigidity during the neonatal period. ${ }^{12}$

\section{Aetiology}

The aetiology of hyperekplexia is not clear. Hyperactivity of cortical neurons, abnormalities of the inhibitory systems of the brain, and abnormalities of the serotoninergic pathways are among the proposed mechanisms. ${ }^{13-16}$ Experimental data suggest the importance of nucleus gigantocellularis in the pathogenesis of the abnormal startle response. ${ }^{17}$ Subtle brainstem vascular anomaly, pontine infarct, lacunar posterior thalamic-subthalamic infarcts, and brainstem encephalopathy have been reported in adults with hyperekplexia. ${ }^{18-21}$ Hyperekplexia is also reported in adults after mild to moderate head injury as part of post-traumatic movement disorder. ${ }^{22}$

\section{Genetic basis}

Hyperekplexia is usually familial, most often autosomal dominant with complete penetrance and variable expression. ${ }^{23}$ Autosomal recessive form and sporadic cases have also been described. ${ }^{24}$ The genetic basis is a mutation usually of the arginine residue 271, transforming $\beta$ alanine and taurine in the glycine receptor from agonists into competitive antagonists. $^{2526}$ This change affects chloride conductance of the $\alpha-1$ subunit of the inhibitory glycine receptors in the caudal pontine reticular formation leading to neuronal hyperexcitability by impairing the glycinergic inhibition. $^{27-29}$ Recently linkage analysis has 
mapped a gene for this disorder to chromosome $5 \mathrm{q} 33-\mathrm{q} 35 .^{30}$

\section{Clinical characteristics}

Hyperekplexia can present in the fetal life as abnormal intrauterine movements, or later at any time from neonatal period to adulthood. ${ }^{20} 31$ The early manifestations include abnormal responses to unexpected auditory, visual, and somesthetic stimuli such as sustained tonic spasm, exaggerated startle response and fetal posture with flexion of forearm and legs, clenched fists, and anxious stare. ${ }^{3}$ The tonic spasms may mimic generalised tonic seizures, leading to apnoea and death. ${ }^{32}$ These spasms are not accompanied by epileptic discharges on electroencephalography (EEG). ${ }^{33}$ Additional features are generalised hypertonia and prominent nocturnal/diurnal myoclonus with apnoea. ${ }^{2} 34$ The hypertonia is apparent only when the infant is awake. ${ }^{7}$ Consistent generalised flexor spasm in response to tapping of the nasal bridge (without habituation) is the clinical hallmark of hyperekplexia, though its mechanism is not very clear. ${ }^{7}$ Though usually there is neither mental nor neurological deficiency, features of diffuse cerebral involvement with developmental delay are seen in some patients. ${ }^{35} 36$ Umbilical, inguinal, and diaphragmatic hernias attributed to hypertonia are seen with increasing frequency in the affected infants. ${ }^{33}$

\section{Risk of SIDS}

Sudden infant death syndrome (SIDS) is well reported in hyperekplexia. ${ }^{37}{ }^{38}$ Central apnoea related to brainstem dysfunction or peripheral apnoea after feeding difficulties with consequent aspiration and respiratory muscle spasm are the proposed mechanisms of SIDS. ${ }^{29}$ Interestingly, the apnoeic episodes are known to disappear spontaneously by 2 years of age. ${ }^{8}$ Sudden death may also be related to complete heart block and apnoea during the seizure-like episodes. $^{32}$

\section{Evolution}

Spontaneous amelioration of the hypertonia with increasing age and delayed gross motor development characterise the evolution of hyperekplexia. ${ }^{3}$ Though the tone is usually almost normal by the age of 3 years, hypertonia may recur in adult life. ${ }^{40}$ The exaggerated startle response, however, persists to adulthood leading to falls on the face or back without loss of consciousness. ${ }^{2}$

\section{Diagnosis}

EEG is usually normal but may show fast spikes (myogenic origin) initially during the tonic spasms, followed by slowing of background activity with eventual flattening corresponding to the phase of apnoea bradycardia and cyanosis. ${ }^{73}$ Electromyography shows a characteristic almost permanent muscular activity with periods of electrical quietness. ${ }^{33}$ Electromyography can be used to monitor treatment and identify minor hyperekplexia. ${ }^{16}$ Nerve conduction velocity is normal. ${ }^{33}$ Proton magnetic resonance spectroscopic imaging
(MRSI) studies have shown reduced intensity of the neuronal marker $\mathrm{N}$-acetylaspartate, choline containing compounds and creatinine in the frontal, central, and right frontal regions. ${ }^{12}$ The topography of EEG abnormalities in the frontal lobes has coincided with MRSI findings in some patients. Whether such neuronal dysfunction represents cortical dysfunction or an epiphenomenon of diencephalic or brainstem abnormalities is currently unknown. No specific computed tomography findings have been reported yet.

\section{Differential diagnosis}

The differential diagnoses of hyperekplexia in the neonatal period include the congenital stiff-man syndrome, startle epilepsy, myoclonic seizures, neonatal tetany, and phenothiazine toxicity. ${ }^{40}{ }^{41}$ Hyperekplexia may also be misdiagnosed as cerebral palsy. ${ }^{7}$ The differential diagnoses in adulthood includes neurological disorders with hypertonia like the Issacs Mertens syndrome, ${ }^{33}$ the jumping Frenchman of Maine, ${ }^{42}$ or somewhat similar clinical entities reported in different parts of the world (for example, miryachit in Siberia ${ }^{43}$ and latah in Malaysia and Indonesia ${ }^{44}$ ), Gilles de la Tourette syndrome, ${ }^{33}$ and Swartz Jampel syndrome. $^{33}$

\section{Treatment}

Clonazepam, a gamma aminobutyric acid (GABA) receptor agonist, is the treatment of choice for hypertonia and apnoeic episodes. ${ }^{45}$ The degree of stiffness, however, may not be significantly influenced by clonazepam. ${ }^{46}$ In contrast phenobarbitone, phenytoin, diazepam, and sodium valproate have not always consistently controlled the hypertonia and/or abnormal startle response. ${ }^{3}$ A simple manoeuvre like forced flexion of the head and legs towards the trunk is known to be life saving when prolonged stiffness impedes respiration. ${ }^{47}$

\section{Conclusion}

Recognition of hyperekplexia in the neonatal period is essential in avoiding erroneous diagnoses like epilepsy. Diagnosis should not be difficult, as consistent generalised flexor spasm in response to tapping of nasal bridge (without habituation) is the clinical hallmark. Though treatment of choice is clonazepam, a simple manoeuvre like forced flexion of the head and the legs towards the trunk can be life saving in presence of prolonged stiffness compromising respiration. Association with recurrent apnoeic spells, cardiac arrhythmia, SIDS, and severe feeding difficulties with apnoea indicates the need for providing home monitoring and appropriate parental counselling.

\footnotetext{
1 Kurczynski TW. Hyperekplexia. Arch Neurol 1983;40:2468 Gordon N. Startle disease or hyperekplexia. Dev Med Child Neurol 1993;35:1015-24.

3 Giacoia GP, Ryan SG. Hyperekplexia associated with apnoea and sudden infant death syndrome. Arch Pediatr Adolesc Med 1994;148:540-3.

4 Kirstein L, Silfverskiold B. A family with emotionally precipitated drop seizures. Acta Paediatr Scand 1958;33: precipitat $471-6$.

5 Suhren O, Bruyn GW, Tunyman JA. Hyperexplexia. A hereditary startle syndrome. F Neurol Sci 1966;3:577-605.
} 
6 Morley DJ, Weaver DD, Garg BP, et al. Hyperexplexia: an Morley DJ, Weaver DD, Garg BP, et al. Hyperexplexia: an inherited

7 Gastaut H, Villeneuve A. The startle disease or hyperekplexia. Pathological surprise reaction. F Neurol Sci 1967;5: $523-42$

8 McMaster P, Cadzow S, Vince J, et al. Hyperekplexia: a rare differential diagnosis of neonatal fits described in a developing country. Ann Trop Paediatr 1999;19:345-8.

9 Gogan P. The startle and orienting reactions in man: a study of their characteristics and habituation. Brain Res 1970;18: $117-35$.

10 Andermann F, Andermann E. Startle disorders of man: hyperekplexia, jumping and startle epilepsy. Brain Dev 1988;10:213-22.

11 Goldstein K, Landis C, Hunt WA, et al. Moro reflex and startle pattern. Arch Neurol Psychiatr 1988;40:322-7.

12 Bernasconi A, Cendes F, Showbridge EA, et al. Spectroscopic imaging of frontal neuronal dysfunction in hyperekscopic imaging of frontal neuron
plexia. Brain 1998;121:1507-12.

13 Mitsumoto I, Schwartzman MJ, Foles SM, et al. Sudden death and paroxysmal autonomic dysfunction in stiffman death and paroxysmal autonomic
syndrome. 7 Neurol 1991;238:91-6.

14 Kelts KA, Harrison J. Hyperekplexia: effective treatment with clonazepam. Ann Neurol 1988;24:309-12.

15 Saenz-Lope E, Herranz Tanario FI, Masdeu JC, et al. Hyperekplexia: a syndrome of pathological startle responses. Ann Neurol 1984;15:36-41

16 Matsumoto J, Fuhr P, Nigro $M$, et al. Physiological abnormalities in hereditary hyperekplexia. Ann Neurol 1992;32:41-50.

17 Halliday AM. The neurophysiology of myoclonic jerking. Excerpta Medica International Congress Series 1975;307:1-29.

18 Gambardella A, Valentino P, Annesi G, et al. Hyperekplexia in a patient with a brainstem vascular anomaly. Acta Neurol Scand 1999;99:255-9.

19 Kimber TE, Thompson PD. Symptomatic hyperekplexia occurring as a result of pontine infarction. Mov Disord 1997; 12:814-6.

20 Fariello RG, Schwartzman RJ, Bealle SS. Hyperekplexia exacerbated by occlusion of posterior thalamoperforate exacerbated by occlusion of posteric

21 Kellet MW, Humphrey PR, Tedman BM, et al. Hyperekplexia and trismus due to brainstem encephalopathy. $\mathscr{f} \mathrm{Neu}$ rol Neurosurg Psychiatry 1998;65:122-5.

22 Krauss JK, Trankle R, Kopp KH. Post traumatic movement disorders after moderate or mild head injury. Mov Disord 1997;12:428-31.

23 Hayashi T, Tachibana H, Kajji T. Hyperekplexia: pedigree studies in 2 families. Am f Med Genet 1991;40:138-43.

24 Rees MI, Andrew M, Jaswad S, et al. Evidence for recessive as well as dominant forms of startle disease (hyperekplexia) caused by mutations in the alpha 1 subunit of the inhibitory glycine receptor. Hum Mol Genet 1994;3:2175-9.

25 Milani N, Dalpra L, del Prete A, et al. A novel mutation (Gln266- $\rightarrow$ His) in the alpha 1 subunit of the inhibitory glycine-receptor gene (GLRA 1 ) in hereditary hyperekplexia. Am f Hum Genet 1996;58:420-2.

26 Shiang R, Ryan SG, Zhu YZ, et al. Mutational analysis of familial and sporadic hyperekplexia. Ann Neurol 1995;38: familial
27 Andrew M, Owen MJ. Hyperekplexia: abnormal startle response due to glycine receptor mutations. Br F Psychiatry $1997 \cdot 170: 106-8$.

28 Langosch D, Laube B, Rundstrom N, et al. Decreased agonist affinity and chloride conductance of mutant glycine receptors associated with human hereditary hyperekplexia. EMBO F 1994;13:4223-8.

29 Shiang R, Ryan SG, Zhu YZ, et al. Mutations in the alpha-1 subunit of the inhibitory glycine receptor cause the dominant neurologic disorder, hyperekplexia. Nat Genet 1993;5:351-8.

30 Vergouwe MN, Tijssen MA, Shiang R, et al. Hyperekplexialike syndromes without mutations in the GLRA 1 gene. Clin Neurol Neurosurg 1997;99:172-8.

31 Leventer RJ, Hopkins JJ, Shield HK. Hyperekplexia as a cause of abnormal intrauterine movements (letter). Lancet 1995;345:461.

32 McAbee GN, Kadakia SK, Sisley KC, et al. Complete heart block in non-familial hyperekplexia. Pediatr Neurol 1995; 12:149-51.

33 Tohier C, Roze JC, David A. Hyperekplexia or stiff baby syndrome. Arch Dis Child 1991;66:460-1.

34 Gherpelli JL, Nogueira AR Jr, Troster EJ, et al. Hyperekplexia, a cause of neonatal apnoea: a case report. Brain Dev 1995;17:114-6.

35 Weaver DD, Morley DJ, Garg BP, et al. Hyperexplexia: nonhereditary stiff baby syndrome. Am $\mathcal{F}$ Dis Child 1982;136: 562.

36 Andermann F, Keene DL, Andermann E, et al. Startle disease or hyperekplexia: further delineation of the syndrome. Brain 1980;103:985-7.

37 Vigeland P, DiCapua N, Bernardina DB. Startle disease: an avoidable cause of sudden infant death. Lancet 1989;i:216-

38 Nigro MA, Lim HCN. Hyperekplexia and sudden neonatal death. Pediatr Neurol 1992;8:221-5.

39 Hunt CT. The cardiorespiratory control hypothesis for sudden infant death syndrome. Clin Perinatol 1992;19:757-71.

40 Sander JE, Layzer RB, Goldsobel AB. Congenital stiffman syndrome. Ann Neurol 1980;8:195-7.

41 Binnie CD. Simple reflex epilepsies. In: Engel J Jr, Pedley TA, eds. Epilepsy. A comprehensive textbook. Vol 3. Philadelphia: Lippincott Raven, 1998: 2489-505.

42 Stevens H. Jumping Frenchmen of Maine. Arch Neurol 1965;12:311-4

43 Hammond WA. Miryachit: a newly described disease of the nervous system, and its analogues. N Y State $7 \mathrm{Med}$ $1884 ; 39: 191-2$

44 Simons RC. The resolution of the latah paradox. I Neurol Ment Dis 1980;168:195-206.

45 Volpe JJ, eds. Neurology of the newborn. 3rd Ed. Philadelphia: WB Saunders, 1995: 189

46 Tijssen MA, Schoemaker HC, Edelbroek PJ, et al. The effects of clonazepam and vigabatrin in hyperekplexia. $\mathcal{F}$ Neurol Sci 1997;149:63-7.

47 Vigevano F, Di Capua M, Dalla Bernadina B. Startle disease: an avoidable cause of sudden infant death. Lancet $1989 ; \mathbf{i}: 216$. 